CATALAN REVIEW

Catalan Review

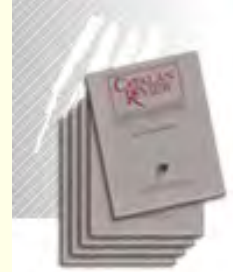

You are accessing the Digital Archive of the Catalan Review Journal.

By accessing and/or using this Digital Archive, you accept and agree to abide by the Terms and Conditions of Use available at http://www.nacs-

catalanstudies.org/catalan review.html

Catalan Review is the premier international scholarly journal devoted to all aspects of Catalan culture. By Catalan culture is understood all manifestations of intellectual and artistic life produced in the Catalan language or in the geographical areas where Catalan is spoken. Catalan Review has been in publication since 1986 .
NORTH

AMERICAN

CATALAN

SOCIETY
Esteu accedint a l'Arxiu Digital del Catalan Review

A l' accedir i / o utilitzar aquest Arxiu Digital, vostè accepta i es compromet a complir els termes i condicions d'ús disponibles a http://www.nacs-

catalanstudies.org/catalan review.html

Catalan Review és la primera revista internacional dedicada a tots els aspectes de la cultura catalana. Per la cultura catalana s'entén totes les manifestacions de la vida intel lectual i artística produïda en llengua catalana o en les zones geogràfiques on es parla català. Catalan Review es publica des de 1986.

\title{
L'estandardització del català, als deu anys del Segon Congrés Internacional de la Llengua Catalana Isidor Marí
}

Catalan Review, Vol. IX, number 2, (1995), p. 77-95 


\title{
L'ESTANDARDITZACIÓ DEL CATALÀ, ALS DEU ANYS DEL SEGON CONGRÉS INTERNACIONAL DE LA LLENGUA CATALANA ISIDOR MARÍ
}

In memoriam Paul L. Garvin

\begin{abstract}
Q uan el final del règim franquista va permetre fer un primer balanç col-lectiu de les necessitats de la nostra societat, les resolucions de l'Area de Llengua del Congrés de Cultura Catalana (1978; 35ss) identificaren la indefinició de l'estàndard com un dels problemes més destacats que calia resoldre. Al llarg dels vint anys següents s'han produit canvis importants en el context sociolingüístic català, que han obert noves possibilitats per al procés d'estandardització de la llengua. Catalunya, les Illes Balears i el País Valencià han accedit a l'autonomia, i el català hi ha esdevingut llengua oficial al costat del castellà. Consegüentment, l'ús del català en certes funcions públiques -administració, ensenyament, comunicació social- ha experimentat un creixement considerable, especialment a Catalunya.

L'any 1986, l'Ârea de Lingüística Social del Segon Congrés Internacional de la Llengua Catalana (Marí, 1992) va fer una nova valoració de l'estat del procés d'estandardització $i$ va concretar les propostes que creia més convenients per a l'estandardització del català durant els anys següents. Poc després, l'Institut d'Estudis Catalans emprenia una nova etapa en la codificació normativa, més activament orientada a la resolució de les necessitats socials. Amb aquest article voldríem resumir les línies principals d'aquest procés i les perspectives actuals en l'estandardització de la llengua catalana.
\end{abstract}

\section{UN ESFORÇ D’ANÀLISI I DE PRECISIÓ CONCEPTUAL}

Al llarg dels darrers anys, la necessitat d'identificar els diferents factors i distingir clarament el caràcter de cadascun dels elements $i$ aspectes que intervenen en el procés d'estandardització ha exigit als sociolingüistes catalans una anàlisi rigorosa i una minuciosa delimitació conceptual i terminològica que, en la meva opinió, constitueix una aportació d'interès general en aquest camp de la sociolingüística. N'és una bona mostra l'obra de Xavier Lamuela (r994), que -avançant a partir 
dels treballs anteriors del Cercle Lingüístic de Praga o Einar Haugenexplora detalladament les relacions d'interdependència entre l'estandardització, com a vessant lingüístic del procés, i el vessant social correlatiu, que ell anomena establiment d'una llengua per tal d'evitar la degradació que considera que ha sofert el terme normalització lingüística. Les llengües establertes es caracteritzen per una practicitat, una capacitat definidora i una adequació completes i per l'autoidentificació primordial que generen en els parlants, les quals determinen la seva funció discriminant principal en la societat: "tots els ciutadans que participen en la vida social amb plenitud de drets les parlen i l'ascens social és regulat des d'aquest coneixement lingüistic previ" (Lamuela, 1994: 8). Tal com ho exposa ell mateix (1994: 64):

"Les llengües establertes acompleixen totes les funcions socials quasi sense limits: són usades per a comunicar en tots els àmbits -amb la possible restricció d'alguns àmbits específics reservats a llengües sectorials o a llengües subordinades-, produeixen una concepció de la realitat completa i acceptada generalment, el seu ús és considerat adequat en qualsevol mena de situació i tenen associats valors que sostenen i justifiquen la seva posició, entre els quals l'associació al nivell més alt d'autoidentificació dels parlants. L'acompliment de la funció discriminant depèn del desenvolupament ple de les altres funcions, que correspon només a la llengua dominant."

Així, l'expansió o, inversament, la regressió d'una llengua (subordinada) es defineixen per cinc processos interactius simètrics (Lamuela, 1994: 104):

a) extensió / retracció de l'ús de la llengua

b) definició de la realitat pròpia dels nous àmbits / pèrdua d'àmbits de definició

c) expansió i estabilització del sistema estilistic / contracció i fragmentació del sistema estilístic

d) adopció de les normes d'ús pròpies de les noves situacions / augment de les restriccions sobre les normes d'us

e) extensió $i$ consolidació de les atribucions de valor que sostenen el procés, entre les quals hi ha l'autoidentificació a través de la llengua / reducció de les connotacions a les que són pròpies d'àmbits fortament caracteritzats i desvaloració de la llengua.

De manera semblant, es poden establir correspondències simètriques entre els processos d'estandardització (expansió estructural) i els de regressió estructural (Lamuela, 1994: 138): 


\section{Regressió estructural}

variabilitat

fragmentarietat

limitació

variabilitat, fragmentarietat i

limitació estilístiques

pèrdua de creativitat

pèrdua de la norma interna

dependència evolutiva

\section{Estandardització}

estabilitat (codificació) unitarietat (codificació) completesa (compleció) estabilitat estilística (cultiu)

creativitat (elaboració) norma segura (codificació) autonomia

En el seu plantejament, doncs, Lamuela parteix d'un concepte molt ampli de l'estandardització, i estableix una útil distinció entre (les formes de) la llengua codificada, la llengua referencial i la llengua estàndard:

"Es pot dir que les formes estàndards són formes referencials que els parlants reconeixen $i$ usen espontàniament de manera adequada $i$ que les formes codificades són formes referencials proposades com a tals però que són poc conegudes pels parlants i usades només amb un esforç conscient. (...) Així:

a) una llengua codificada disposa d'una varietat o de formes referencials, que pot ser que ho siguin només d'una manera potencial i explícita,

b) una llengua estandarditzada disposa d'una varietat o de formes amb un caràcter referencial necessàriament actual i implícit." (Lamuela, 1994: Ir9)

Són precisions conceptuals que convé tenir en compte en la resta de les nostres consideracions sobre l'estat actual de l'estandardització.

\section{Un BALANÇ ALS DEU ANYS DEL SEGON CONGRÉS INTERNACIONAL DE LA Llengua CATALANA}

Tant els treballs com les conclusions de l'Àrea 3 del Segon Congrés Internacional de la Llengua Catalana es van estructurar en quatre ponències o seccions, dedicades respectivament als temes següents:

I. Les varietats dialectals i els estudis dialectològics.

2. Els registres o varietats funcionals i la terminologia.

3. Les traduccions $i$ les interferències.

4. El procés d'estandardització.

En el nostre balanç sobre l'acompliment de les resolucions d'aquesta Àrea al cap de deu anys del Congrés seguirem doncs aquesta mateixa estructuració. 


\section{VARIETATS DIALECTALS I ESTUDIS DIALECTOLÖGICS}

La primera conclusió d'aquesta secció declarava la urgència de l'estudi monogràfic de les varietats dialectals sobre bases científiques, en els aspectes fonètics, lèxics, morfològics $i$ sintàctics, per tal de conèixer amb profunditat els codis orals de la nostra llengua. Així mateix, proposava que, donada la dispersió existent en els materials recollits fins aleshores, es fes un buidatge d'aquests fons $i$ es constituis un banc general de dades de tot el domini lingüístic, en connexió amb els treballs lèxics en curs de realització a l'Institut d'Estudis Catalans, com a base per a l'estandardització de l'idioma.

En els deu anys transcorreguts es pot dir que els estudis dialectològics han prosseguit a un ritme notable, per més que no s'hagin ordenat d'acord amb un programa global que asseguri plenament la unitat de mètode, l'absència de buits i la integració general de totes les dades obtingudes. Una relació d'alguns dels treballs més destacables ${ }^{t}$ permet corroborar aquestes apreciacions.

Respecte a la constitució d'un banc general de dades dialectològiques, en certa manera es pot considerar iniciada amb la informatització de l'Atles Lingüístic del Domini Català a l'Institut d'Estudis Catalans $i$ el Corpus Oral Dialectal en curs d'elaboració a la Universitat de Barcelona. Tanmateix, sembla que cal no oblidar la conveniència d'un marc indicatiu global per a la recerca dialectològica, acordat entre les

${ }^{1}$ BeLtran, Vicent. 1994. El parlar de Callosa d'en Sarrià i de les valls de Tàrberza $i$ de Guadalest. València: Generalitat Valenciana.

Valenciana,

Colomina, Jordi. 1991. El valencià de la Marina Baixa. València: Generalitat

Coll, Pep. 1991. El parlar del Pallars. Barcelona. Empúries.

CORBERA, Jaume. 1993. Nou vocabulari de barbarismes del català de Mallorca. Palma: El Tall.

Espaulella, Laura, et al. 1993. Variació generacional en el parlar de la Garriga. La Garriga: Contrapunt.

GIMENO, Lluís. 1994 Estudi lingüistic dels parlars de les comarques del Nord de Castelló. Castelló: Societat Castellonenca de Cultura.

MONTOYA, Brauli. 1989. La interferència lingüistica al Sud valencià. València: Generalitat Valenciana. Catalans.

Pons, Lídia. 1992. Iodització i apitxament al Vallès. Barcelona: Institut d'Estudis

Riera, Manel. 1992. La llengua catalana a Andorra. Institut d'Estudis Andorrans.

SANNA, Josep. 1988. Diccionari català de l'Alguer. Catalans,

SisTAC, Ramon. 1993. El ribagorģà a l'Alta Llitera. Barcelona: Institut d'Estudis

VILA, Carme. 1988. El parlar de la Plana de Vic. Manresa: Caixa de Manresa. 
universitats $\mathrm{i}$ les institucions públiques, amb un programa de treball que permeti obtenir dades dels parlars menys estudiats i relacionar sistemàticament entre elles les bases de dades resultants, amb una estructura distribuïda que doni unitat al conjunt respectant l'autonomia de cada nucli. Aquesta podria ser una de les línies d'acció del Centre de Recursos Lingüístics en vies de constitució actualment a Catalunya. D'altra banda, convindria tenir en compte l'estreta relació que hi ha entre les dades d'interès dialectològic $i$ les que procedeixen de recerques sobre la cultura popular oral o la història oral. Convindria, probablement, coordinar i sistematitzar l'activitat de les fonoteques existents a l'àrea de llengua catalana.

La segona conclusió d'aquesta secció recomanava, davant l'empobriment progressiu de les locucions i frases fetes, la confecció de reculls a totes les zones de l'àmbit lingüístic, amb llur introducció en els diccionaris de sinònims, i el seu ús entre els escriptors i els mitjans de comunicació.

Resulta difícil valorar quina ha estat en els darrers deu anys l'evolució de l'ús de les locucions i frases fetes. Han aparegut, però, estudis o reculls interessants i útils per a la divulgació d'aquestes formes expressives, ${ }^{2}$ que permetrien emprendre una acció pedagògica i de difusió, en el marc d'un conjunt de mesures orientades a l'enriquiment de la llengua comuna.

La tercera conclusió recomanava la incorporació al Diccionari general dels mots de les grans zones dialectals que compleixen requisits de genuinitat, extensió geogràfica, necessitat expressiva, etc. i fer possible que aquests mots fossin vehiculats en els mitjans de comunicació.

Es pot afirmar en aquest cas que l'aparició del nou Diccionari de la llengua catalana de l'Institut d'Estudis Catalans a finals de 1995 ha representat l'acompliment d'aquesta recomanació. Amb motiu de l'actualització del diccionari normatiu, en efecte, $s$ 'hi ha introduitt una àmplia selecció de mots de gran part del territori lingüístic, els quals a més no han estat marcats com a propis d'una contrada determinada més que quan la seva difusió era estrictament local. D'aquesta forma se subratlla que es tracta de mots disponibles per al conjunt de la comunitat lingứstica. Naturalment, la vehiculació efectiva d'aquest lèxic en els mitjans de comunicació es veu afavorida amb aquest nou plantejament, però caldria assegurar-la amb orientacions concretes sobre l'ús del lèxic comú en els diferents mitjans.

${ }^{2}$ Entre aquests, podem destacar els treballs sobre paremiologia de Maria Conca i l'aparició de reculls locals com el Refranyer menorquí de Josep Pons, publicat per l'Institur Menorquí d'Estudis (1993). 
Finalment, la quarta conclusió d'aquest primer apartat expressava la conveniència que el coneixement i la comprensió dels dialectes tinguessin un lloc important en tots els nivells d'ensenyament.

No és fàcil tampoc fer una valoració de l'acompliment d'aquest punt, però en línies generals es pot afirmar que, si bé l'extensió de l'ensenyament de català ha permès ampliar el coneixement i la comprensió dels grans dialectes, som lluny encara de l'acceptació general d'una valoració equilibrada de l'interès de tots els parlars dialectals i de la importància de la seva aportació a l'enriquiment de la llengua comuna. Tanmateix, algun esforç s'ha fet en aquesta línia, com l'edició de l'obra Mapes per a l'estudi de la llengua catalana, que inclou informacions dialectològiques, històriques $i$ sociolingüístiques. ${ }^{3}$

\section{REGISTRES LINGÜISTICS I TERMINOLOGIA}

Les conclusions relatives a aquesta secció s'iniciaven amb la constatació dels condicionaments que representen dues dificultats extralingüístiques: d'una banda, els obstacles que implica per a I'elaboració dels registres especialitzats la marginació del català per part d'altres llengües en els àmbits d'ús corresponents; de l'altra, la manca d'una intercomunicació normal entre tots els territoris de llengua catalana. Aquests condicionaments subsisteixen en línies generals, amb algunes diferències respecte a l'any 1986.

En alguns àmbits s'ha produït una certa extensió de l'ús especialitzat del català, com per exemple en les institucions polítiques i administratives, en el sistema educatiu -i singularment en l'ensenyament superior-, en alguns mitjans de comunicació, en la publicitat i els doblatges, en les versions catalanes de productes informàtics, en alguns sectors de serveis (sanitat, finances, subministraments, transports), en el món esportiu arran dels Jocs Olímpics, ${ }^{4}$ etc. No obstant això, fins i tot en aquests casos ha mancat una actuació coordinada i unitària entre els diversos territoris de llengua catalana.

Resta pendent, per tant, en bona part la primera proposta que havia plantejat aquesta secció, per tal que s'establís una coordinació institucional entre les administracions, l'Institut d'Estudis Catalans, les universitats, els mitjans de comunicació i altres sectors destacats d'usuaris,

$3 \mathrm{La}$ primera edició, de 5.000 exemplars, com a Suplement 6 de la revista "COM/ensenyar català als adults" (Generalitat de Catalunya. Barcelona, 1.989). EUMO en va fer una reedició posterior (Vic, 1992).

4 En són un bon exempleles col-leccions de reglaments i de diccionaris terminològics dels esports publicades per Enciclopèdia Catalana, fruit de la col-laboració entre la Generalitat de Catalunya, el TERMCAT i les institucions esportives. 
amb Ja finalitat d'organitzar conjuntament l'elaboració dels registres especialitzats més necessaris, en estreta relació amb l'extensió de l'ús de la nostra llengua i amb una capacitat d'incidència general a tot el territori lingüístic.

Fins i tot els avanços parcials -sectorials o bilaterals- que s'han produit des de 1986 en aquesta direcció es poden considerar ben limitats. És el cas, per exemple, del funcionament de la Comissió Assessora de Llenguatge Administratiu de Catalunya, ${ }^{5}$ en la qual participa un representant de la Secció Filològica de l'IEC, i que manté contactes ocasionals amb els serveis lingüístics d'altres territoris per tal de mantenir la coherència del llenguatge administratiu. $O$ del treball efectuat en l'àmbit jurídic, amb motiu de les actuacions de normalització lingüística de l'Administració de Justícia a Catalunya. Cal tenir en compte també els acords establerts pel Centre de Terminologia TERMCAT amb universitats de les Balears i del País Valencià i els contactes entre les universitats de la nostra àrea lingüística, aplegades fa poc en l'Institut Joan Lluís Vives, que constitueixen ara per ara les expectatives més clares de coordinació entre els territoris de llengua catalana.

No hi ha dubte que aquesta escassa coordinació institucional és un dels dèficits persistents més greus, amb consequències que van molt enllà de l'elaboració dels registres especialitzats i afecten el conjunt del procés d'estandardització.

La segona proposta d'aquesta secció es referia a la necessitat de sistemes d'informació i assessorament dels usuaris i de programes satisfactoris de formació lingüística dels professionals, integrats en el seu currículum educatiu normal, més que concebuts com a reciclatges addicionals.

Respecte al primer punt, es pot afirmar que hi ha hagut un considerable desplegament de serveis d'assessorament lingüístic i que especialment al Principat de Catalunya han seguit un procés de sistematització i especialització complementària de les seves funcions: així, els serveis que atenen els usuaris de forma directa $\mathrm{i}$ immediata sectorialment o territorialment (des del Consorci per a la Normalització Lingüística) poden traslladar els dubtes que no estiguin en condicions de resoldre a serveis més especialitzats (el TERMCAT per a assumptes terminològics i el Servei d'Assessorament Lingüistic de la Generalitat de Catalunya per a la resta de temes). S'ha iniciat també la posada en

${ }^{5}$ A més de les convencions especificament administratives elaborades per aquesta Comissió, podem destacar pel seu interès general la relativa a l'ús de Majúscules $i$ minúscules. Barcelona: Departament de Cultura de la Generalitat de Catalunya. 1992 (2a ed.).

${ }^{6}$ En són mostres el Manual de documents juridics en català-Barcelona: CDC. 1995i el Formulari juridic -Barcelona: Consell dels Il-lustres Col-legis d'Advocats de Catalunya. $1995^{-}$, entre d'altres. 
marxa d'un sistema integral d'assessorament lingüístic, constituït de moment pel Telèfon Lingüístic (amb resposta automàtica per telèfon i fax) i el servei Linguatex (per videotex). La necessitat més urgent i immediata en aquest camp se centra en l'accés telemàtic via Internet a totes aquestes informacions, pendent de decisions institucionals en el moment de redactar aquest text.

Els llibres o manuals d'estil corporatiu constitueixen una altra modalitat d'informació a l'usuari que ha assolit resultats ben destacables. Són dignes d'esment, en aquest camp, els treballs de Daniel Cassany, ${ }^{7}$ Joan Solà ${ }^{8}$, sobretot, el grup constituït per Josep M. Mestres, Joan Costa, Mireia Oliva i Ricard Fité?

Pel que fa a la formació lingüística dels professionals, es pot dir que ha experimentat alguns progressos en casos concrets, amb l'elaboració de cursos o materials de formació específics, com el curs per a policies locals publicat pel Consorci per a la Normalització Lingüística de Catalunya ${ }^{10}$ o les aportacions de Lluís Marquet i Carles Riera en l'àmbit del català científic i tècnic. " En general, però, només en la mesura que ha avançat l'ús docent del català es pot considerar que ha progressat la formació lingüística en el currículum ordinari dels diversos ensenyaments. La incorporació sistemàtica d'elements de formació lingüística suficients en els diversos plans d'estudis professionals, ocupacionals, tècnics o d'altres especialitzacions superiors resta encara per fer i seria desitjable que hi hagués una acció institucional conjunta en aquest sentit per part dels responsables d'educació de tot el territori de llengua catalana.

Una tercera proposta d'aquesta secció feia referència a la difusió de pautes de comportament lingüístic que promoguessin l'ús del català, i específicament dels registres i les varietats adequats a cada situació d'ús. No és fàcil mesurar l'efecte que han tingut els esforços realitzats en aquesta línia, però és remarcable la difusió que ha tingut els darrers deu anys l'enfocament de la diversitat lingüística basat en els plantejaments sistèmico-funcionals de Halliday, que foren presentats a la mateixa ponèn-

7 Llibre d'estil. Caixa d'Estalvis i Pensions de Barcelona, rg9t.

${ }^{8}$ Llibre d'estil de l'Ajuntament de Barcelona. Barcelona: Consorci per a la Normalització Lingüistica. 1995.

${ }^{9}$ Manual d'estil. La redacció i l'edició de textos. Vic: Eumo et al. 1995.

${ }^{10}$ Dolors Badia et al. Parlar és la clau. Vol. I (1991) i vol II (1992).

"Lluîs Marquer, El llenguatge cientifici i tècnic. Barcelona: Associació d'Enginyers Industrials de Catalunya. 1993. Carles Riera, Manual de català tècnic $i$ cientific, Barcelona: Claret (1992) i El llenguatge científic català. Barcelona: Barcanova. 1994. 
cia del Segon Congrés per un dels seus principals exponents, Michael Gregory. Un treball de vocació divulgadora sobre les varietats i registres del catala ${ }^{12}$ i la seva utilització va ser àmpliament difós a partir de $1986 \mathrm{i}$ aquest enfocament ha tingut un ressồ considerable en llibres de text escolars i en medis educatius en general. També hi han contribuït indirectament, sens dubte, altres estudis sobre registres lingüístics, com l'excel-lent treball de Lluís Payrató sobre el Català col-loquial' ${ }^{13}$

Les propostes quarta $i$ cinquena d'aquest apartat tractaven d'aspectes més concrets de la llengua als mitjans de comunicació. Per exemple, propugnaven acords entre les universitats i els centres televisius per a la millora de la qualitat lingüística, reclamaven als responsables de la televisió una presència proporcionada de totes les modalitats regionals de la llengua estàndard i proposaven una formació lingüística més intensa dels professionals de la informació, amb el suport dels serveis d'assessorament necessaris i d'uns criteris definits per a l'estàndard oral.

L'aparició de la Proposta per a un estàndard oral de la llengua catalana presentada per l'Institut d'Estudis Catalans ${ }^{14}$ ha constituit un punt de referència en la línia de les propostes esmentades. Altres treballs publicats per Josep Lacreu, Antoni Ferrando, Vicent Salvador i Toni Molla ${ }^{15}$ han tingut una utilitat remarcable. La tasca de formació de professionals -especialment a la Facultat de Ciències de la Informació de la Universitat Autònoma de Barcelona- ha estat també intensa. ${ }^{16} \mathrm{~A}$ més, són nombrosos els mitjans -orals o escrits- que compten amb un llibre d'estil ${ }^{17}$ o un servei propi d'assessorament lingüistic. Tot i això, és necessari establir sistemes més eficaços de seguiment i millora de la qualitat lingüística en els mitjans, en una línia que no tendeixi a accentuar els controls de caràcter purista, sinó que faciliti l'adequació, la naturalitat i la creativitat genuina com a part de la millora dels professionals de la comunicació.

Les conclusions d'aquesta ponència feien també diverses consideracions respecte a la terminologia. Aquestes consideracions reiteraven la necessitat d'establir les prioritats de l'activitat terminològica d'acord

${ }^{12}$ Els perfils del català, llibret i vídeo elaborats per Daniel Cassany i Isidor Marí, publicats pel Departament de Cultura de la Generalitat de Catalunya el 1990.

${ }^{13}$ Universitat de València, 1988.

${ }^{14}$ Fascicle I: Fonètica (1990). Fascicle II: Morfologia (1992),

${ }^{15} \mathrm{~J}$. Lacreu, Manual d'ús de l'estiandard oral. Universitat de València (199z, 2a ed.); A. Ferrando (ed.), La llengua als mitjans de comunicació, obra editada per la mateixa universitat el 1990; Vicent Salvador (ed.), Teletextos (2 vols.), Univ. de València (1998 i 1990); Toni Mollì, La llengua dels mitjans de comunicació, Bromera (Alzira, 1990).

${ }^{16}$ N'és un bon exemple el Manual de pronunciació publicat per Josep-Anton Castellanos. Eumo. Vic, 1993. 
amb una visió unitària de les necessitats específiques i les possibilitats de cada territori de parla catalana i partint del reconeixement de l'Institut d'Estudis Catalans com a única autoritat lingüística acadèmica per a la llengua catalana, que ha d'atorgar el vistiplau a la nova terminologia a través dels canals de supervisió que es considerin més adients.

Més concretament, se subratllava que l'estandardització de la llengua general i la de la terminologia són processos relacionats, però díferents, per tal com responen a necessitats distintes. Així mateix, s'afegia que en el cas d'àrees temàtiques amb tradició terminològica autòctona cal recollir les variants territorials $i$ tenir-les en compte a l'hora d'estandarditzar els termes, juntament amb el vessant internacional que també ha de respectar la terminologia especialitzada.

Des d'un punt de vista organitzatiu, les conclusions plantejaven la vehiculació de les accions d'estandardització terminològica de les diverses administracions de l'àrea lingüística catalana a través d'un organisme coordinador i planificador únic per a la llengua catalana, que representés unitàriament la terminologia catalana a l'Estat $i$ als organismes terminològics internacionals.

Totes aquestes consideracions reflecteixen el model organitzatiu que aleshores es començava a establir, amb la creació el 1985 del Centre de Terminologia TERMCAT com a fruit d'un acord institucional entre la Generalitat de Catalunya i l'Institut d'Estudis Catalans.

Transcorreguts deu anys, es pot confirmar la utilitat d'un centre de terminologia que actuï com a punt de trobada entre els especialistes dels diversos camps del coneixement, l'autoritat lingüística acadèmica, els poders públics encarregats de dirigir la política lingüística i els professionals de la llengua. L'adopció pel TERMCAT l'any 1994 de la personalitat jurídica de consorci - entre la Generalitat de Catalunya (departaments de Cultura, Ensenyament, Universitats i Recerca), l'Institut d'Estudis Catalans i el Consorci per a la Normalització Lingüística- ha representat la renovació del compromís institucional de cooperació en aquest camp.

La tasca del TERMCAT en suport de l'elaboració de terminologia catalana ha consistit en l'establiment i la difusió d'unes bases metodològiques consistents, ${ }^{18}$ la formació terminològica en diverses modalitats-des de sessions bàsiques per a docents i professionals, fins a les

${ }^{77}$ Llibre d'estil de l'Avui (inèdit), 1988. Llibre d'estil del Diari de Barcelona. Empúries. Barcelona, 1987. Eusebi Coromina, El 9 Now: Manual de redacciö $i$ estil. Eumo. Vic, 1991. El català aTV3. Llibre d'estil. Ed. 62. Barcelona, 1995.

${ }^{18}$ Metodologia del treball terminològic. Barcelona: Departament de Cultura de la Generalitat de Catalunya. 1990. D'altra banda, la publicació de l'obra de M. TeresaCabré La terminologia -Barcelona: Empúries. 1992- ha representat una sòlida fonamentació teòrica d'aquesta nova disciplina. 
estades de formació especialitzada concertades amb universitats com a part d'estudis de tercer cicle, passant per cursos de terminologia puntual o sectorial-, l'assessorament metodològic i documental, la coordinació o la direcció de nombrosos treballs terminogràfics, etc.

En el vessant de la normalització terminològica, l'assessorament. dels especialistes en el terreny conceptual i de viabilitat sociolingüísti$\mathrm{ca}^{19}$ ha complementat la validació formal de diversos milers de termes pel Consell Supervisor, presidit per un membre de la Secció Filològica. Els nous termes s'han divulgat àmpliament per mitjà d'un Full de difusió de neologismes i s'han establert i difós orientacions d'abast més general a través de la col-lecció "Criteris lingüístics per a la terminologia." ${ }^{20}$

L'atenció anual d'unes Io.000 consultes, la intervenció en més d'un centenar de publicacions de tota mena - des de cartells, tríptics o lèxics de caràcter divulgatiu, fins a col-leccions de diccionaris de gran abast, ${ }^{21}$ a vegades de caràcter visual ${ }^{22} \mathrm{o}$ en suport informàtic- ${ }^{23}$ són exemples de la considerable projecció de la informació terminològica aconseguida els darrers anys.

Actualment, el Centre de Terminologia TERMCAT compta amb un sòlid reconeixement internacional, patent amb l'acord efectuat amb el Comitè Olímpic d'Atlanta per a l'intercanvi de terminologia dels esports o amb la participació en els projectes europeus d'enginyeria lingüística POINTER i INTERVAL.

A part del TERMCAT, altres institucions han realitzat treballs terminològics molt remarcables: per exemple, algunes universitats, com la Politècnica de Catalunya o la Universitat de Barcelona, que publiquen sengles colleccions de diccionaris; l'Acadèmia de Ciències Mèdiques, que ha promogut el Diccionari enciclopèdic de medicina ${ }^{24}$ dirigit pel

${ }^{19}$ Per mitjà de dossiers de normalització, sessions de normalització conjuntes amb especialistes institucionalment representatius o comitès i subcomitès tècnics formalment constituïts, segons l'abast i la complexitat del treball.

20. L. Manlleus i calcs lingüistics en els treballs de terminologia catalana (1990).

2 Formació de termes amb elements cultes (1990).

3. Guia d'establiment de criteris per a la denominació catalana d'animals (1992). 4 Formació del plural dels manlleus (1992).

Tots els títols han estat editats pel Departament de Cultura de la Generalitat de Catalunya.

${ }^{21}$ Com la col-leccció de diccionaris dels esports olímpics, la de Diccionaris terminològics adreçats a la universitat, la de Lèxics per a la indústria a la de Terminologies.

${ }^{22}$ Com el Diccionari visual de la construcció, en curs de publicació per part del Departament de Política Territorial i Obres Públiques.

${ }^{23}$ Com la terminologia i fraseologia d'assegurances en suport Multiterm, apareguda el 1996.

${ }^{44}$ Editat per Enciclopèdia Catalana el 1990. 
doctor Oriol Casassas; l'ITEC, el Col-legi d'Enginyers, la Fundació Torrens Ibern, etc.

Tot $\mathrm{i}$ això, les necessitats terminològiques són tan àmplies que encara és enorme la quantitat de feina pendent i cal remarcar la necessitat d'una implicació més clara de les institucions de tot el territori lingüístic en aquesta tas $\mathrm{Ca}_{1}$ aconseguida en part a les Balears per mitjà d'un conveni entre el Govern Balear i el Gabinet de Terminologia de la Universitat, que al seu torn és centre col-laborador del TERMCAT. L'accés telemàtic generalitzat a la informació terminològica reclama especialment $\mathrm{i}$ amb urgència, tal com hem dit abans, el suport institucional necessari.

\section{LES TRADUCCIONS I LES INTEREERÈNCIES}

Les conclusions referides a la traducció, a més d'insistir en la necessitat d'impugnar la supremacia social d'altres llengües en el nostre territori lingüístic, apuntaven tres aspectes a tenir en compte: l'extensió de la traducció i la interpretació (al/del català) a tots els camps socials en què correspondria a una cultura normal, una regulació jurídica satisfactòria de les activitats de traducció-interpretació per part dels poders públics competents a l'àrea de llengua catalana i la necessitat de disposar de mitjans ergonòmics que garanteixin la qualitat dels productes.

No hi ha dubte que els darrers deu anys hi ha hagut evolucions significatives en l'extensió social de les activitats de traducció. La formació de traductors, per exemple, ha rebut un impuls decisiu amb la creació de la llicenciatura de traducció i la implantació d'aquests estudis a diverses universitats de l'àrea lingüística catalana. La doble oficialitat lingüística representa un altre factor de dinamització d'aquestes activitats en l'àmbit administratiu. Els doblatges de productes audiovisuals (per al cinema, la televisió o el vídeo) i les traduccions literàries o de textos especialitzats han adquirit un relleu més i més gran, indiscutiblement. De totes formes, no podem negar que encara som lluny del nivell de traducció que seria normal entre el català i altres llengües, especialment en els terrenys tècnics o culturals més relacionats amb el funcionament del mercat, que han iniciat un creixement vertiginós en aquests anys, amb la mundialització de les relacions econòmiques i culturals. Una iniciativa singularment important en aquesta línia és el projecte de traducció automàtica anglès-català ITACA, realitzat per la UAB i INCYTA amb el patrocini de la Generalitat de Catalunya. Ara bé, en la nostra opinió, caldria començar per fer un balanç detallat de la situació actual en els diversos àmbits, en la línia de l'Estudi del mercat de la tra- 
ducció realitzat pel projecte TELELANG, ${ }^{25}$ com a base per a definir una política global prou consistent en aquest camp.

La regulació jurídica de les activitats de traducció no s'ha vist gaire modificada els darrers anys, si no és en el terreny de la traducció i la interpretació jurades, que ha estat objecte d'un decret de la Generalitat de Catalunya en virtut del qual s'ha establert un certificat especific.

La necessitat de mitjans i eines que facilitin l'ergonomia de la traducció ha estat en part resolta amb l'aparició de nombrosos diccionaris interlingüistics, editats principalment per Enciclopèdia Catalana, i pels diccionaris terminològics abans esmentats. Han començat a aparèixer també diccionaris en suport CD-ROM, com l'Hiperdiccionari d'Enciclopèdia Catalana, i programes informàtics de suport a la traducció, com Multiterm, disponible en versió catalana i acompanyat de diccionaris en suport disquet. La implantació social d'aquestes eines és encara reduïda, però no hi ha dubte que en els anys vinents modificaran significativament el treball del traductor.

Pel que $\mathrm{fa}$ a les interferències, les conclusions remarcaven la gravetat especial que tenen en situacions de minorització com la de la nostra llengua, en les quals la interferència esdevé unidireccional i desmesurada. En últim terme, se subratllava, el control de la interferència no podrà aconseguir-se sense una autèntica normalització del català, que modifiqui la situació d'interposició i de substitució que pateix. Per tal d'analitzar els processos d'interferència i escollir les mesures adequades d'actuació, les conclusions proposaven com a prerequisit l'estudi del medi i del rerefons dels exemples d'interferència, complementat amb estudis sobre els usos i recursos propis més productius de la nostra llengua. Aquest tipus d'estudis, constataven les conclusions, no han estat usuals en la lingüística catalana, que tradicionalment ha tendit a abordar les interferències com a barbarismes i des d'una òptica de puresa o correcció. Es destacava, per tant, la necessitat d'una coordinació dels estudis i d'una actuació urgent i decidida de l'autoritat lingüística, en funció de l'estat actual de la llengua, de la seva evolució immediata i de les necessitats dels qui en són professionals. Com a mesura d'orientació i de control més urgent, s'apuntava la necessitat d'una política sobre el manlleu lèxic de formes lingüístiques forasteres.

Aquesta última demanda es pot considerar que ha estat atesa en el camp de la terminologia, amb l'aparició de les orientacions sobre Manlleus $i$ calcs lingüístics en els treballs de terminologia catalana publi-

${ }^{25}$ TELELANG és un projecte del programa europeu d'Aplicacions Telemàtiques realitzat el 1995 , en el qual ha participat el CIDEM. Dec aquestes informacions a la Dra. Montserrat Meya, repesentant catalana del grup del projecte. 
cades pel TERMCAT. ${ }^{26}$ També s'han publicat alguns estudis concrets sobre la interferència $i$ el contacte lingüístic o comparacions contrastives entre català i castellà. ${ }^{27}$ Tanmateix, subsisteix la urgència d'una acció global sistemàtica en aquest camp, tal com havien subratllat les conclusions de 1986. La collaboració entre l'Institut d'Estudis Catalans, les universitats i els responsables de la política lingüística i l'administració educativa podria ser la manera més adequada d'abordar aquesta tasca.

\section{ESTAT DEL PROCÉS D’ESTANDARDITZACIÓ}

Les resolucions de la quarta secció de l'Àrea de Lingüística Social van ser indubtablement les de més abast, i es referien en primer lloc a les condicions necessàries per a aconseguir la plena viabilitat del procés d'estandardització. En aquest sentit, s'afirmava que el procés de normalització lingüística ha de ser inequivocament unitari, per mitjà d'una intervenció institucional coordinada a tot el domini lingǘstic, que parteixi del reconeixement explícit de la unitat de la llengua per part de totes les institucions autonòmiques i estatals implicades. A continuació, se subratllava la necessitat d'establir una organització conjunta i permanent, amb representacions proporcionades de tots els territoris de llengua catalana, encarregada de vetllar pel caràcter unitari, composicional i confluent del procés d'estandardització.

Més concretament, es remarcava com a objectiu essencial la consolidació d'un espai comunicatiu comú, sobretot audiovisual, i s'insistia en la necessitat de clarificar per mitjà de l'ensenyament la naturalesa i les funcions de la llengua estàndard, especialment a les zones on el procés d'estandardització està més endarrerit.

Pel que fa a l'Institut d'Estudis Catalans, les conclusions plantejaven el seu reconeixement general com a autoritat acadèmica per a la llengua catalana, alhora que consideraven necessària la seva ampliació amb representants de tot el territori lingüístic i l'actualització de la normativa, amb una especial referència a la necessitat d'un nou diccionari normatiu. Tanmateix, es remarcava que la codificació es podia considerar acomplerta en línies generals, i que l'atenció preferent s'ha-

${ }^{26} \mathrm{~V}$. nota 20.

27 Neus Farràs \& Carme Garcia, Morfosintaxi comparada del català $i$ el castellà. Barcelona: Empúries. 1993.

Miquel Pueyo, Llengües en contacte en la comunitat catalana. Univ. de València, 1991.

Joan A. Argenté \& Lluís Payrató, "Contacte de llengües: antecedents i constitució de l'àmbit de recerca." Dins Límits, núm. 8 (1990).

S'hi poden incloure, també, els treballs de Corbera i Montoya ja esmentats a lapartat de dialectologia. 
via de centrar en la vehiculació unitària de les propostes normatives, en la comprovació de la seva implantació social per mitjà de la realització de proves d'ús i en l'orientació del procés d'estandardització i elaboració dels registres especialitzats. En aquest sentit, s'esmentava la necessitat de propostes relatives a l'estandardització de la llengua oral pròpia dels mitjans de comunicació.

Transcorreguts deu anys després d'aquestes propostes, cal reconèixer que no $s$ 'ha aconseguit la coordinació institucional imprescindible ni l'acceptació general de la unitat de la llengua, qüestionada encara sobretot per sectors determinats de la societat valenciana, emparant-se en la denominació estatutària de valencià. Lamentablement, ni $\tan$ sols les institucions de govern que assumeixen la unitat de llengua han arribat a establir òrgans de coordinació comuns i permanents en les seves polítiques de normalització lingüística.

És cert que el sistema educatiu ha contribuït a difondre el model de llengua estàndard i que hi ha hagut alguns avenços en la consecució d'un espai comunicatiu-limitats, però, a la recepció de TV3 a gran part del territori lingüístic, i no a un intercanvi televisiu general. També han aparegut estudis teòrics o monogràfics ben interessants per a la consolidació de l'estàndard català, a més del ja esmentat de Lamuela. ${ }^{28}$ Sigui com sigui, l'absència de coordinació institucional és l’obstacle més important en la consecució d'un procés d'estandardització general, sense desfasaments ni desequilibris territorials. ${ }^{29}$

\footnotetext{
${ }^{28}$ Per exemple:

Antoni M. Badia, Gramàtica de la llengua catalana. Barcelona: Enciclopèdia Catalana. 1993.

Gabriel Bibiloni, L'estandarització de la llengua catalana: la tasca feta i la tasca a fer. Manacor: Patronat de l'Escola Municipal de Mallorquí. 1993.

Jordi Colomina, Els valencians $i$ la lengua normativa. Alacant: Institut de Cultura "Juan Gil-Albert." 1995 . 1993.

Bernat Joan, Llengua estàndard en l'ensenyament. Vilassar de Mar: Oikos-Tau.

Joan Martí (ed.), Processos de normalització: l'extensió de l'ús social i la normativització. Barcelona: Columna, 1991.

Josep M. Pujol \& Joan Solà, Ortotipografia. Barcelona: Columna. 1925.

Josep Ruaix, Punts conflictius del català. Barcelona. Barcanova. 1989 .

Josep Ruaix, Observacions crítiques i pràctiques sobre el català d'avui (2 vol.) Moià:

Ruaix. 1994 i 1995 .

Joan Solà, Qüestions controvertides de sintaxi catalana. Barcelona: Edicions 62. 1987.

Joan Solà, Lingüistica i normativa. Barcelona. Empúries. 1990.

Joan Solà, La llengua, una convenció dialèctica. Barcelona: Columna. 1993.

Joan Solà, Sintaxi normativa: estat de la qüestió. Barcelona: Empúries. 1994.

Joan Solà \&c Josep M. Pujol, Tractat de puntuació. Barcelona: Columna. 1990.

${ }^{29} \mathrm{Val}$ a dir que el Pla general de normalització lingüística aprovat per la Generalitat de Catalunya el 1995 preveu l'establiment d'acords institucionals, peró les declaracions favorables d'altres institucions de govern no s'han concretat encara en una coopertiva efectiva.
} 
Respecte a l'Institut d'Estudis Catalans, encara que el seu reconeixement oficial explícit només s'ha produit a Catalunya, fins i tot per mitjà d'una llei del Parlament, es pot considerar que la seva autoritat acadèmica tan sols és qüestionada pels sectors de la societat valenciana que, com hem dit, no accepten la unitat lingüística.

Conscients d'aquesta situació, l'Institut Interuniversitari de Filologia Valenciana i la Generalitat Valenciana van publicar el 1995 una gramàtica i un diccionari que -sense allunyar-se dels criteris normatius generals- poguessin servir de referents valencians oficials. Es aviat encara per fer cap valoració sobre els efectes d'aquestes publicacions, però els canvis polítics ocorreguts poc després no permeten ser gaire optimistes respecte a la seva implantació social.

L'ampliació de les representacions territorials de l'Institut -especialment de la Secció Filològica-i l'activació de les seves tasques d'actualització de la normativa han estat d'altra banda fets molt evidents a partír de 1986. Els dos punts més destacats en les conclusions com a necessitats més immediates -l'actualització del diccionari normatiu i la definició d'una proposta d'estàndard per als mitjans de comunicacióes poden considerar també resolts amb la publicació del Diccionari de la llengua catalana i la Proposta per a un estàndard oral de l'Institut, als quals ja hem fet referència anteriorment. ${ }^{30} \mathrm{D}$ 'altra banda, també s'ha iniciat l'elaboració d'una nova gramàtica normativa de l'Institut d'Estudis Catalans, La tasca feta en aquest camp ha estat doncs molt remarcable, encara que puguin restar alguns punts per resoldre i que tant la implicació de les institucions de govern en el suport a l'Institut com la implantació territorial d'aquest siguin clarament millorables.

\section{CONCLUSIÓ GENERAL}

Com a síntesi de totes les valoracions precedents, podem afirmar que:

1) El procés d'estandardització de la llengua catalana encara es troba fortament limitat i condicionat per la manca d'un procés unitari de normalització lingüística, que exigeix una decidida intervenció institucional coordinada a tot el territori lingüístic.

2) És imprescindible, doncs, que les institucions polítiques del nostre àmbit lingüístic assumeixin de forma oficial, explícita i definitiva la

${ }^{30}$ Així mateix, molts dels punts concrets apuntats com a pendents per la ponència han estat objecte de regulació específica: mots compostos amb $s$-líquida inicial, ús del guionet, increment del tercer grup verbal en valencia, grafia final de la primera persona del present d'indicatiu en els parlars balears, etc. Vegeu Documents de la secció Filològica, $I i$ II. Barcelona, 1990-1992. 
unitat de la llengua, i que estableixin òrgans comuns i permanents de coordinació en la normalització lingüística. Només així serà possible resoldre els desequilibris i desfasaments observables en el procés d'estandardització,

3) Per tal d'assegurar la complementarietat entre l'estandardització i l'extensió de l'ús de la llengua, cal trobar les formes adequades d'articulació de totes aquestes institucions polítiques amb l'Institut d'Estudis Catalans, i ampliar-ne la composició i la implantació territorial perquè arribi a ser proporcionada en el conjunt de les terres de llengua catalana.

4) En aquesta acció coordinada, cal vetllar perquè el sistema educatiu proporcioni l'adequada formació lingüística a tots els nivells, perquè es produeixi una cooperació autènticament recíproca en el camp dels mitjans de comunicació i les indústries culturals $\mathrm{i}$, de manera molt especial, per assegurar la disponibilitat en llengua catalana de les noves eines, recursos i serveis informàtics, amb una política conjunta en l'àmbit de l'enginyeria lingüística.

5) Lingüísticament, és necessari completar l'actualització de la normativa de la llengua general -especialment en els aspectes gramaticals i gràfics- per part de l'Institut d'Estudis Catalans, i establir les formes adequades de cooperació entre els poders públics, l'autoritat acadèmica $\mathrm{i}$ les institucions dels diversos àmbits d'especialitat per tal d'avançar sense desajustaments en l'elaboració dels registres específics i la terminologia pròpia de cada sector.

\author{
ISIDOR MARÍ \\ UNIVERSITAT OBERTA DE CATALUYA
}

\title{
REFERENCIES
}

CONGRÉS DE CULTURA CATALANA.1978. Resolucions (I). Barcelona: Curial et al.

LAMUela, Xavier. 1994. Estandardització i establiment de les llengües. Barcelona: Edicions 62.

MAR1, Isidor (ed.). I992. Segon Congrés Internacional de la Llengua Catalana. IV. Area 3. Lingüistica Social. Palma: Universitat de les Illes Balears. 


\title{
ENGLISH ABSTRACT
}

\begin{abstract}
Standardization of Catalan, ten years after the Second International Congress on Catalan Language.
\end{abstract}

The resolutions of the Catalan Culture Congress (1978) identified standardization of Catalan as one of the most important problems to be solved. Along the last 20 years, important changes took place in the sociolinguistic context of Catalan, opening new possibilities for the language standardization: Catalonia, the Balearic Islands, and Valencian Country have reached a political autonomy and Catalan has become an official language besides Castilian or Spanish. As a consequence, the use of Catalan in several public functions -administration, education, mass comunication- has considerably increased, especially in Catalonia.

In 1986, the Social Linguistics Section of the Second International Congress on Catalan Language (Marí, 1992) made a new evaluation of the standardization process and proposed the best ways to improve the standardization of Catalan during the next years. A few years later, the Institute for Catalan Studies intensified its codification activities according to social needs.

This article is a brief presentation of the main features of this process, analyzing the acomplishment of the resolutions on language standardization of the Second International Congress on Catalan Language along the last ten years (1986-1996).

It firstly concentrates on theoretical advances on standardization processes analysis, namely the work of Xavier Lamuela (1994) and, after reviewing the Second International Congress resolutions on language standardization, it concludes with several remarks:

1) The standardization process of Catalan is still strongly limited by the lack of a unified language policy for the whole language community.

2) It is therefore essential that political institutions explicitly and actively assume the unity of Catalan and establish a common body to coordinate the language policy.

3) To ensure that the standardization of Catalan and the extension 
of its social functions are complementary, language policy institutions should maintain close links to the Institute for Catalan Studies activities.

4) The education system, the mass media, cultural industries, informatics and language engineering should be first priorities in this coordinated language policy.

5) It would be useful that the Institute for Catalan Studies put to day the grammar and several graphical points, and that LSP elaboration and terminological activities are given a main importance. 